\title{
ESTUDIOS
}

\section{El Comité de Basilea y la regulación internacional de la supervisión financiera y sus efectos en las cajas de ahorro españolas}

\section{Juan Antonio Jimber del Río' y Ma del Carmen López Martín}

Resumen: La crisis financiera que ha sacudido a la economía internacional ha obligado a adoptar nuevas medidas de control y de redefinición del capital, así como de las relaciones entre las autoridades estatales y las entidades financieras. Este artículo revisa las medidas adoptadas por el Comité de Basilea en la nueva regulación macroprudencial bautizada como Basilea III, analizando sus efectos en las Cajas de Ahorros españolas.

Palabras clave: Crisis financiera, Comité de Basilea, capital básico, capital core, Fondo de Reestructuración Ordenada Bancaria.

Fecha de recepción: 10 de diciembre de $201 \mathrm{I}$.

Fecha de admisión definitiva: 10 de septiembre de 2012.

\footnotetext{
1 Juan Antonio Jimber es profesor asociado en el Departamento de Economía, Sociología y Política Agraria de la Universidad de Córdoba, área de Economía Financiera y Contabilidad. Ma del Carmen López Martín es profesora de la Facultad de Ciencias Empresariales-ETEA.
} 
The Basel Committee and the international regulation of financial supervision

Abstract: The financial crisis that has rocked the international economy has led to new measures of control and a redefinition of capital, as well as of the relations between state authorities and financial institutions. This article reviews the steps taken by the Basel Committee in the new prudential regulation dubbed Basel III, analyzing its effects on Spanish savings banks.

Key words: Financial crisis, Basel Committee, Common Equity, Core capital, Bank Restructuring Fund.

\section{Le Comité de Bâle et la réglementa- tion internationale de la supervision financière}

Résumé: La crise financière qui a secoué l'économie internationale a conduità de nouvelles mesures de contrôle et de redéfinition du capital, ainsi qu'à de nouvelles relations entre les autorités étatiques et les institutions financières. Cet article passe en revue les mesures prises par le Comité de Bâle dans le nouveau règlement macroprudentiel baptisé Bâle III, en analysant ses effets sur les caisses d'épargne espagnoles.

Mots Clés: Crise financière, Comité de Bâle, capital de base, fonds propres de base, Fonds de Restructuration de la Banque.

\section{Introducción y marco económico internacional}

La crisis financiera que actualmente sacude a la economía occidental está dejando una abrumadora carga a las autoridades estatales, especialmente en los países industriales. Las recientes reacciones del mercado revelan que en algunos países los estímulos fiscales han llegado a su límite. Diversas economías industriales requieren de inmediato una consolidación fiscal contundente, que deberá ir acompañada de reformas estructurales que faciliten el crecimiento y aseguren la sostenibilidad fiscal a largo plazo. Pese a los intensos estímulos monetarios y fiscales que se han aplicado, el PIB de la mayoría de las economías avanzadas aún se sitúa muy por debajo de su nivel previo a la crisis. En cuanto a los niveles de deuda pública, su rápido crecimiento plantea cuestiones urgentes sobre la sostenibilidad de las finanzas públicas.

Aunque los bancos han reforzado sus reservas de capital y sus beneficios han crecido gracias a diversos factores transitorios, siguen expuestos a nuevas pérdidas por impago y a la dotación de de sus activos contaminados (préstamos promotores de viviendas y suelo pendientes de recalificación urbanística en zonas de demanda 
actual nula). Aunque los bancos de los países en crisis han avanzado en la recomposición de sus balances, el proceso dista mucho de haber concluido.

Los esfuerzos por reestructurar y reforzar el sistema financiero no deben cejar. Los niveles de deuda pública que arrastran numerosos países industriales han tomado una senda insostenible. Los déficits presupuestarios actuales, en parte cíclicos pero también inflados por las políticas de respuesta a la crisis y a las necesidades del propio sistema financiero, son elevados en proporción al PIB. Al mismo tiempo, el aumento del gasto vinculado al envejecimiento de la población se prevé considerable en las próximas décadas. Lo ocurrido recientemente en Grecia y en otras naciones de Europa meridional ha mostrado lo rápido que pueden propagarse a otros países las dudas de los inversionistas sobre la solidez de las cuentas públicas de una economía. Además, los altos niveles de deuda pública pueden lastrar el crecimiento económico a largo plazo y, en último término, constituir una amenaza para la estabilidad monetaria.

Basilea III surge como una mejora del sistema anterior (conocido como Basilea II) y, además, intenta dar una respuesta a la reciente tormenta financiera, cuyo diseño pretende protegernos de crisis futuras.

Consideremos el extraordinario panorama financiero contemporáneo a la última ICBS ${ }^{2}$.

Sólo en septiembre de 2008:

- Lehman Brothers se declaró en quiebra,

- los otros grandes bancos de inversión estadounidenses se transformaron en conglomerados bancarios,

- Fannie Mae y Freddie Mac fueron nacionalizadas,

- AIG fue rescatada justo al borde del colapso,

- Fortis, el conglomerado financiero, fue desmembrado y vendido,

- el mayor banco comercial de Islandia cayó, y seguidamente su sistema bancario,

${ }^{2}$ El Comité alienta los contactos y la cooperación entre sus miembros y otras autoridades de supervisión bancaria, distribuye a los supervisores de todo el mundo sus documentos de trabajo y proporciona orientación sobre cuestiones de supervisión bancaria. Con el fin de intensificar los contactos entre supervisores, organiza con carácter bianual la Conferencia Internacional de Supervisores Bancarios (ICBS, por sus siglas en inglés). 
- numerosos países tuvieron que ofrecer enormes paquetes de ayuda en auxilio de sus bancos,

- Irlanda tuvo que ser rescatada por el déficit del país generado por salvar a su vez a las entidades financieras,

- Grecia fue rescatada en dos ocasiones,

- Portugal fue rescatado (a partir de entonces comenzó a hablarse del grupo de países denominado $\mathrm{PIG}^{3}$ ).

Todo esto aconteció en el apogeo de la crisis. Desde entonces, el sistema financiero y bancario ha sido estabilizado y ahora nos encontramos en la senda de la recuperación. Pero su coste ha sido elevado: muchos presupuestos públicos se han deteriorado enormemente a causa del ingente tamaño de las ayudas oficiales. Los efectos de la crisis financiera se propagaron además a la economía real, con el resultado de pérdidas de riqueza y de puestos de trabajo. Este proceso aún no ha concluido y los riesgos persisten.

Aunque dolorosa y costosa, la crisis ha brindado, sin embargo, una oportunidad para acometer reformas a largo plazo que son necesarias para dotar a los bancos y al sistema financiero de una mayor resistencia para afrontar futuros periodos de tensión. El Comité de Basilea se ha situado en el centro de esta agenda reformadora, cristalizada en la cumbre de líderes del G-20 celebrada el año pasado en Pittsburgh. ${ }^{4}$

También se ha ampliado el número de miembros del Comité, aumentándolo hasta 27 jurisdicciones 5 . Esta mayor participación proporciona beneficios, tanto en términos de conocimiento como de legitimidad. La razón de ser de la regulación financiera es sencilla: si se dejara a los bancos a sus anchas, sus niveles de capital y liquidez

\footnotetext{
3 PIG (cerdo) Portugal, Irlanda y Grecia, está por ver si se une la S de Spain, para que en el argot financiero el grupo se denomine PIGS (cerdos).

${ }^{4}$ Después de elaborar este texto se han llevado a cabo otras medidas con similares objetivos en cuyo desarrollo no entramos

${ }^{5}$ El Comité está compuesto por autoridades de Alemania, Arabia Saudí, Argentina, Australia, Bélgica, Brasil, Canadá, China, Corea, España, Estados Unidos, Francia, Hong Kong, India, Indonesia, Italia, Japón, Luxemburgo, México, Países Bajos, Reino Unido, Rusia, Singapur, Sudáfrica, Suecia, Suiza y Turquía. Los países están representados por sus bancos centrales y también por la autoridad con la responsabilidad formal de la supervisión prudencial del sector bancario, cuando no la realiza el banco central (generalmente las superintendencias de bancos o entidades/ instituciones financieras).
} 
serían insuficientes. Basilea Ill supone un refuerzo fundamental, y en algunos casos un cambio radical, de las normas internacionales de capital ${ }^{6}$.

La promoción de la estabilidad financiera exige un marco de política amplio, en el que la política prudencial es sólo uno de sus componentes. Otro elemento son las políticas macroeconómicas, ya sea monetaria o fiscal, que son clave para el fomento de la estabilidad financiera (pues son las que determinarán que el entorno alcance las características apropiadas para alcanzar dicha estabilidad). Un tercer elemento clave es la disciplina de mercado.

A riesgo de simplificar en exceso, nos gustaría enfatizar que la implementación de Basilea III7 implicará:

(1) mejorar considerablemente la calidad del capital bancario;

(2) elevar de forma significativa el nivel exigido de capital;

(3) reducir el riesgo sistémico; y

(4) conceder suficiente tiempo para una transición suave hacia el nuevo régimen.

Para entender los cambios que supone el nuevo sistema, en el esquema siguiente se muestran los cambios experimentados por los sucesivos marcos regulatorios (Basilea I, II y III). Mientras que en el sistema inicial (Basilea I) se establecían los requerimientos de capital según el riesgo de las inversiones teniendo en cuenta el riesgo de crédito de las mismas, en Basilea II se produce una ampliación de las exigencias, al tiempo que el sistema se hace más completo y se establecen los tres pilares que sustentan la supervisión: la exigencia de unos recursos propios mínimos (determinados teniendo en cuenta no sólo el riesgo de crédito, sino también el riesgo de mercado y el denominado riesgo operativo $u$ operacional; igualmente se establecen distintos sistemas para medir estos riesgos); la supervisión bancaria (las autoridades, con un mayor protagonismo, deben asegurarse de que los procedimientos adoptados por las entidades sean idóneos y de que cuentan con una unidad de evaluación y administración de riesgos independiente); y la disciplina de mercado (que obliga a que tanto las entidades como los supervisores rindan

\footnotetext{
${ }^{6}$ Recordemos que, aunque la normativa de Basilea no es de obligado cumplimiento, en el caso europeo, las autoridades han optado por adaptar esta normativa al acervo comunitario.

${ }^{7}$ Caruana, J. (2010) "Basilea III: hacia un sistema financiero más seguro", Banco de Pagos Internacionales, $3^{a}$ Conferencia Internacional de Banca, Madrid, 15 de septiembre de 2010.
} 


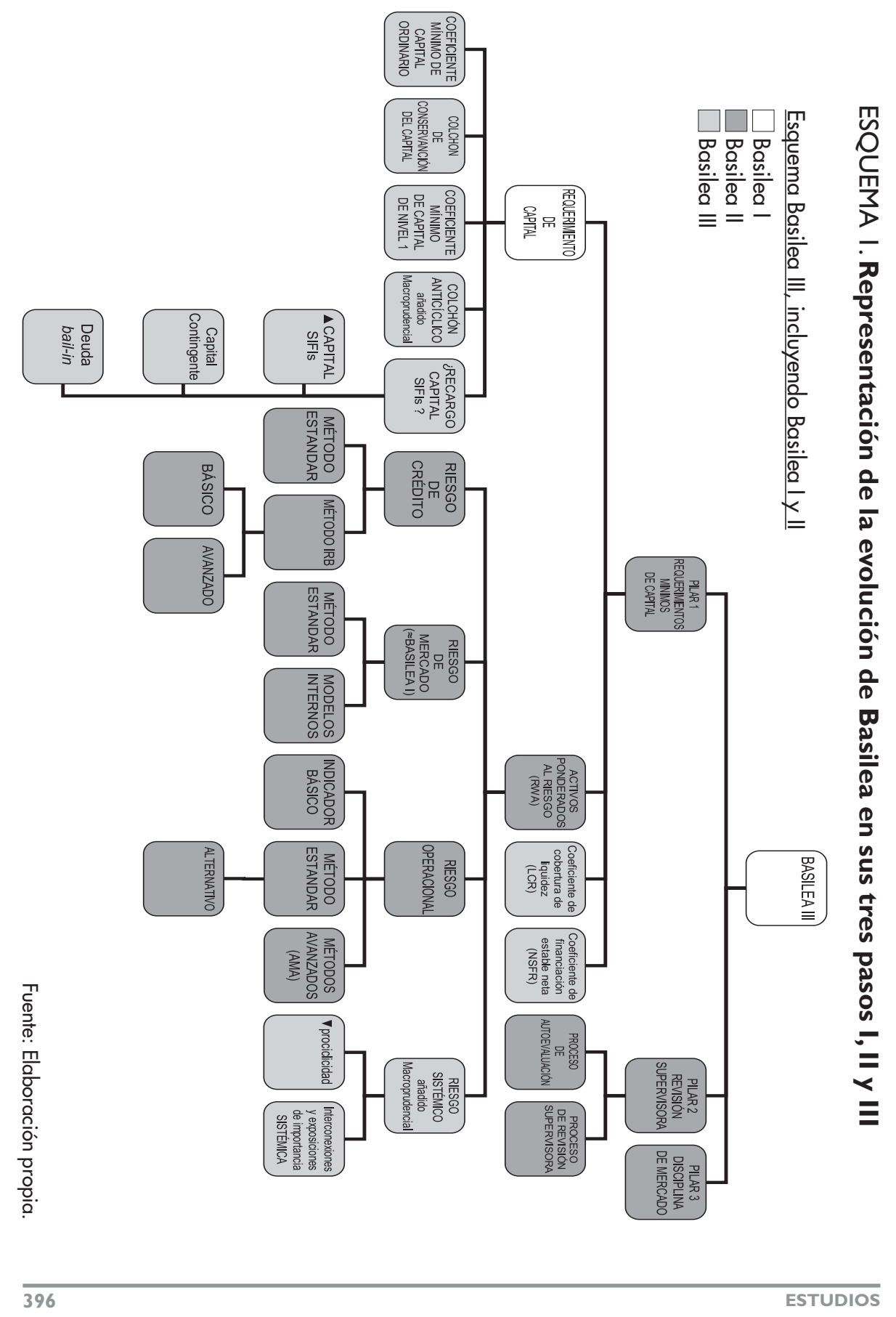


cuentas públicamente para que sea conocida la situación de riesgo y de capital de las instituciones). Finalmente, Basilea III, como se detalla en los apartados siguientes, extiende de nuevo el marco de supervisión, incorporando nuevas exigencias (coeficiente de liquidez y de financiación estable neta), ampliando los riesgos cubiertos con la inclusión del riesgo sistémico y aumentando las exigencias de capital.

\section{Mejora de la calidad del capital}

La nueva definición de capital es tan importante como su nuevo nivel más elevado, y supuso una paso adelante esencial, ya que era imperativo definir la composición del capital antes de ajustar su nivel. ¿¿Cuáles son los nuevos requerimientos de capital? Un aspecto fundamental es el mayor énfasis en lo que se conoce como "capital ordinario o básico", es decir, el componente de mayor calidad dentro del capital de cada banco. Además, la definición del capital ordinario o básico ("Common

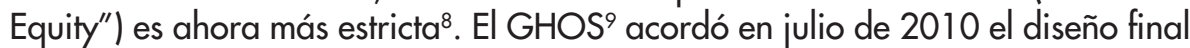
de los ajustes regulatorios, que se van a aplicar en general a escala de "Common Equity". A continuación se destaca el tratamiento de algunos de estos ajustes:

1. Intereses minoritarios: Se admite la inclusión parcial en "Common Equity" de intereses minoritarios en filiales bancarias.

2. Fondo de comercio y otro activo intangible: deberán ser deducidos del "Common Equity".

3. Inversiones en el capital de instituciones financieras (banca, valores y seguros) que no consoliden:

\footnotetext{
${ }^{8}$ En concreto, los conceptos que se incluyen en este concepto son, fundamentalmente, el capital desembolsado junto con la prima de emisión en su caso, las reservas y resultados positivos del ejercicio, ciertas plusvalías y la deuda convertible obligatoriamente en acciones.

${ }^{9}$ El Grupo de Gobernadores de Bancos Centrales y Jefes de Supervisión (GHOS), que es el órgano de vigilancia del Comité de Basilea, estableció el marco general para Basilea III en septiembre de 2009 y el Comité presentó propuestas concretas en diciembre de 2009. Estos documentos de consulta sirvieron de base para la respuesta del Comité a la crisis financiera y se insertan dentro de las iniciativas internacionales para reforzar el sistema regulador financiero refrendadas por los Líderes del G-20. En su reunión de julio de 2010, el GHOS acordó los principales elementos del paquete de reformas y en septiembre de 2010 presentó el calibrado y calendario de transición para la implementación de las medidas.
} 
a) La deducción será total si las entidades son del grupo o existen acuerdos recíprocos de inversión.

b) Si el banco tiene más de un 10\% de la entidad emisora (inversión significativa), el tratamiento se recoge en el punto 4 .

c) Si el banco tiene inversiones en otras instituciones financieras y sumadas las inversiones suponen más del 10\% del "Common Equity" del propio banco, se deducirá el importe que exceda del $10 \%$.

4. Activos fiscales diferidos por diferencias temporales e inversiones significativas en instituciones financieras que no consoliden: se establece una franquicia, de tal manera que sólo se deduce el exceso sobre dicha franquicia. La franquicia tiene un límite individual y otro global. La franquicia para cada elemento no puede superar el 10\% del "Common Equity". Además, la entidad deberá deducir el importe por el que la suma de los dos elementos citados exceda del 15\% del "Common Equity".

Al mejorar la calidad del capital, Basilea III aumentará considerablemente la capacidad de los bancos para absorber pérdidas. Con Basilea II, los requerimientos mínimos para el capital ordinario y el capital de Nivel 1 son del $2 \%$ y el $4 \%$ respectivamente, mientras que con la nueva definición, esos niveles de capital sólo supondrían aproximadamente el $1 \%$ y el $2 \%$ respectivamente para un banco representativo con actividad internacional ${ }^{10}$. Las nuevas normas implican que, si el resto de factores permanece igual, los bancos tendrán que elevar su componente de capital ordinario para cumplir los requerimientos mínimos.

La nueva definición de capital se aplicará progresivamente a lo largo de cinco años: los requerimientos se introducirán en 2013 y su implementación definitiva no será hasta finales de 2017. Los instrumentos que ya no puedan considerarse como capital de Nivel 1 distinto del capital ordinario o como capital de Nivel 2 dejarán de reconocerse paulatinamente en un horizonte de 10 años a partir del 1 de enero de 2013.

\footnotetext{
10 Debe tenerse en cuenta que, al cambiar las partidas que forma parte del capital ordinario y del capital de Nivel 1, es como si, en la práctica, estos valores disminuyesen.
} 


\section{Más capital}

Ahora bien, no basta con tener mejor capital, también se necesita más capital en el sector bancario, como la crisis se encargó de demostrar. Es por ello que el órgano de gobierno del Comité de Basilea ha acordado elevar los requerimientos de capital.

Un elemento clave de Basilea III es el aumento del capital ordinario mínimo"1 hasta el 4,5\%. Este nivel es mucho más alto que el $2 \%$ contemplado en Basilea II, que equivaldría aproximadamente al $1 \%$ para un banco representativo cuando el capital se calcula con la nueva definición más estricta.

Asimismo, el requerimiento mínimo para el capital de Nivel $1^{12}$ se elevará hasta el $6 \%$, frente al $4 \%$ en la normativa actual.

Además, los bancos deberán mantener un "colchón de conservación" del 2,5\% del capital ordinario para poder hacer frente a futuros periodos de tensión. El incumplimiento de esta exigencia tiene consecuencias directas: conforme el capital bancario se acerque al mínimo requerido, se irá restringiendo la distribución de beneficios del banco (ej. dividendos, recompra de acciones, bonificaciones) hasta que se reponga el capital. Esto ayudará a que el banco pueda disponer de capital suficiente para respaldar sus operaciones en los periodos de tensión. Para poder cumplir su función, se requiere que el colchón de conservación tenga plena capacidad para absorber pérdidas $y$, por tanto, debe estar formado por los mismos componentes del "Common Equity". Este colchón se diseña como un requerimiento adicional al requerimiento mínimo de "Common Equity". Así pues, en total los bancos deberán mantener en situaciones normales al menos un $7 \%$ de capital ordinario.

A lo anterior hay que añadir un "colchón anticíclico" que oscila entre $0 \%$ y $2,5 \%$ de los activos ponderados por riesgo. El funcionamiento básico de estos "colchones anticíclicos" consiste en que las entidades deben constituir estos "colchones" en momentos de bonanza económica para poder consumirlos, y así compensar las

\footnotetext{
${ }^{11}$ Como ya se ha indicado, este concepto corresponde, fundamentalmente, al capital desembolsado y las reservas.

${ }^{12}$ Más adelante se detallan los conceptos incluidos en el capital del nivel 1
} 
pérdidas crediticias, en momentos de recesión ${ }^{13}$. De esta forma se quiere evitar que las entidades reduzcan la oferta de crédito durante las fases bajistas para poder cumplir con las exigencias regulatorias del capital.

Estos requerimientos de capital basados en el riesgo se complementarán con un coeficiente de apalancamiento ajeno al riesgo, que ayudará a evitar la excesiva acumulación de apalancamiento en el sistema, complementará a los requerimientos basados en el riesgo y mitigará el riesgo de los modelos. En enero de 2013 comenzará a probarse un coeficiente de apalancamiento mínimo del $3 \%$ para el capital de Nivel 1, es decir, la relación entre el capital de Nivel 1 (calculado con la definición más rigurosa de Basilea III) y los activos totales del banco no ponderados por riesgo más las exposiciones fuera de balance. Este periodo de prueba permitirá al Comité comprobar la evolución de los coeficientes de apalancamiento actuales a lo largo del ciclo económico, el impacto que esta evolución puede tener en sus modelos de negocios y cómo este coeficiente interactúa con los requerimientos basados en el riesgo.

\section{Una dimensión macroprudencial para afrontar riesgos sistémicos}

El tercer elemento clave del nuevo marco de capital regulatorio proporciona una dimensión macroprudencial para hacer frente a riesgos sistémicos, es decir, el riesgo de alteraciones del sistema financiero capaces de desestabilizar la macroeconomía. Aunque el refuerzo de la base de capital de los bancos hará más fuerte al sistema bancario, no basta con centrarse en las entidades a título individual, ya que el riesgo del sistema en su conjunto es mayor que la suma de los riesgos de cada entidad, como ha quedado de manifiesto durante la crisis financiera de 2007.

Para limitar con eficacia el riesgo sistémico hay que combatir en dos grandes frentes. El primero es reducir la prociclicidad, es decir, la tendencia del sistema financiero a amplificar los altibajos de la economía real. El segundo es tener en cuenta las interconexiones y exposiciones comunes entre instituciones financieras, especialmente para aquellas que se consideran de importancia sistémica.

\footnotetext{
${ }^{13}$ Se trata, como vemos, de un funcionamiento similar al de las provisiones genéricas que el Banco de España obligó a cumplir a las entidades españolas.
} 
Basilea III representa en este sentido un giro fundamental en el diseño de la regulación financiera. La necesidad consciente de complementar la supervisión financiera a nivel micro con la dimensión macroprudencial es algo que hasta ahora no había encontrado cabida en la regulación financiera.

En cuanto a la prociclicidad, Basilea III promueve la acumulación de capital en los buenos momentos para disponer de él en los periodos de tensión.

En primer lugar, como ya hemos mencionado, el nuevo requerimiento de capital ordinario pasa a ser del 7\%, incluyendo un colchón de conservación de capital del $2,5 \%$. Su propósito es asegurar que los bancos mantengan una reserva de capital que sirva para absorber pérdidas durante periodos de tensión y evitar así que su capital caiga por debajo del mínimo obligatorio. Esto reducirá la posibilidad de que se produzca un círculo vicioso de pérdidas y recortes de crédito en comparación con las normas anteriores.

En segundo lugar, un elemento clave de Basilea III para limitar la prociclicidad será el colchón de capital anticíclico, que se ha calibrado en un rango del 0-2,5\%. Este capital se dotará cuando las autoridades nacionales consideren que el crecimiento crediticio agregado está agravando el riesgo sistémico, y se liberará en las fases bajistas del ciclo. De este modo, se reduciría por ejemplo el riesgo de que el crédito disponible pueda verse restringido por los requerimientos de capital regulatorio. Su intención es por tanto mitigar la prociclicidad y atenuar el impacto de los altibajos del ciclo financiero.

Aparte de reducir la prociclicidad, Basilea III también permitirá un mejor tratamiento del riesgo sistémico derivado de las interconexiones y exposiciones comunes entre instituciones individuales. El principio fundamental en este sentido es asegurar que las normas se calibran con respecto a la contribución de cada institución al riesgo del sistema en su conjunto, no sólo con respecto a su propio riesgo. El FSB ${ }^{14}$ y el Comité de Basilea están analizando diversas medidas para aplicar a estas instituciones financieras de importancia sistémica (SIFIs en inglés). El marco de Basilea III exige que estas instituciones tengan capacidad de absorber pérdidas por encima de lo que dicta la norma. El Comité de Basilea y el Consejo de Estabilidad Financiera

${ }^{14}$ El Consejo de Estabilidad Financiera (FSB, siglas en inglés), fue creado por el Grupo de los Veinte (G20) en su cumbre de Londres el pasado abril de 2011 . Se creó como una versión renovada y ampliada del Foro de Estabilidad Financiera, un grupo asesor creado en 1999 para promover la estabilidad financiera internacional a través de una mayor cooperación internacional y un mayor intercambio de información. 
(FSB) están examinando la pertinencia de otras medidas para mitigar el riesgo sistémico, como por ejemplo imponer un recargo de capital a las entidades más grandes y con mayor importancia sistémica (las llamadas SIFI) o la capacidad de la deuda "bail-in" para que los prestamistas de las SIFI soporten más riesgos en caso de quiebra ${ }^{15}$. Además, se sigue trabajando para reforzar los regímenes de resolución bancaria. Los Gobernadores y Jefes de Supervisión apoyan el objetivo de fortalecer la absorción de pérdidas por parte de instrumentos de capital de Nivel 1 distintos del capital ordinario (por ejemplo, las reservas) y de Nivel 2.

\section{Disposiciones transitorias}

Desde el comienzo de la crisis, los bancos han desplegado considerables esfuerzos para elevar sus niveles de capital. Aun así, los resultados preliminares del estudio integral sobre el impacto cuantitativo llevado a cabo por el Comité a finales de 2009 muestran que los grandes bancos en su conjunto necesitarán bastante capital adicional para hacer frente a estos nuevos requerimientos. Los bancos más pequeños, que son especialmente importantes para el préstamo a las PYMES, ya cumplen en gran medida estas normas más estrictas.

Los Gobernadores y Jefes de Supervisión también acordaron una serie de disposiciones transitorias para la aplicación de las nuevas normas. De este modo, contribuirán a que el sector bancario pueda cumplir las nuevas normas de capital con un nivel razonable de retención de beneficios y ampliación de capital, mientras siguen concediendo crédito al conjunto de la economía. Las disposiciones transitorias son las siguientes:

La aplicación de estas normas por los países miembros comenzará el 1 de enero de 2013. Con anterioridad a esa fecha, los países deberán haber traspuesto las nuevas normas a sus respectivas legislaciones y regulaciones. A partir del 1 de enero de 2013, se exigirá a los bancos cumplir los siguientes requerimientos mínimos con relación a sus activos ponderados por riesgo ("RWAs", en la terminología anglosajona)

15 El "bail-in" o rescate desde dentro es un mecanismo que consiste, esencialmente, en convertir a los acreedores en accionistas del banco, de forma que la deuda se convierte en capital cuando una entidad tiene problemas con el fin de recapitalizarse rápidamente. 
- 3,5\% capital ordinario/RWAs;

- 4,5\% capital Nivel 1/RWAs; y

- $8,0 \%$ capital total/RWAs.

Entre el 1 de enero de 2013 y el 1 de enero de 2015 se irá produciendo de forma progresiva un ajuste de los requerimientos mínimos, en el sentido siguiente:

- El 1 de enero de 2013, el requerimiento mínimo de capital ordinario pasará del $2 \%$ actual al $3,5 \%$ y el de capital de Nivel 1 lo hará del $4 \%$ al $4,5 \%$.

- El 1 de enero de 2014, los bancos deberán mantener como mínimo un 4\% de capital ordinario y un 5,5\% de capital de Nivel 1.

- El 1 de enero de 2015, los porcentajes serán del 4,5\% y el 6\% respectivamente. El requerimiento para los recursos propios totales (también denominado capital total)se mantiene en su actual $8 \%$, por lo que no necesita ningún proceso de transición. La diferencia entre el requerimiento de capital total del $8 \%$ y el requerimiento de capital de Nivel 1 puede cubrirse con capital de Nivel 2 y con otras formas de capital de mayor calidad.

El colchón de conservación del capital se aplicará paulatinamente entre el 1 de enero de 2016 y el final de 2018, para entrar plenamente en vigor el 1 de enero de 2019. Las autoridades nacionales tienen discrecionalidad para imponer periodos de transición más breves y deberán hacerlo cuando lo consideren adecuado.

Aquellos bancos que cumplan el coeficiente mínimo durante el periodo de transición pero que aún se sitúen por debajo del $7 \%$ fijado como objetivo para el capital ordinario (coeficiente mínimo más colchón de conservación) deberán aplicar políticas prudentes de retención de beneficios con el fin de alcanzar lo antes posible el nivel exigido para el colchón de conservación.

Las inyecciones de capital público existentes se podrán computar excepcionalmente hasta el 1 de enero de 2018 (es decir, dejarán de ser considerados recursos propios). Los instrumentos que ya no puedan considerarse como capital de Nivel 1 distinto del capital ordinario o como capital de Nivel 2 dejarán de reconocerse paulatinamente en un horizonte de 10 años a partir del 1 de enero de 2013. Partiendo del importe nominal de dichos instrumentos vigente el 1 de enero de 2013 , su reconocimiento se limitará al $90 \%$ a partir de esa fecha y cada año se reducirá este límite en 10 puntos porcentuales. Asimismo, aquellos instrumentos 
que incluyan incentivos para su amortización se dejarán de reconocer en su fecha de vencimiento efectiva.

Los instrumentos que no cumplan los criterios para ser considerados como capital de Nivel 1 ordinario serán excluidos de inmediato el 1 de enero de 2013. Sin embargo, se excluirán progresivamente siguiendo los plazos descritos en el apartado anterior aquellos instrumentos que cumplan las tres condiciones siguientes:

(1) hayan sido emitidos por una entidad distinta de una sociedad por acciones ("non-joint stock companies");

(2) se contabilicen como "patrimonio" ("equity") según las normas contables en vigor; $y$

(3) se reconozcan de forma ilimitada como capital de Nivel 1 en la legislación bancaria nacional en vigor.

Sólo los instrumentos emitidos antes de la publicación del presente comunicado podrán beneficiarse de las disposiciones transitorias aquí mencionadas.

En cuanto a la liquidez, para dar respuesta a las presiones que se produjeron durante la crisis, el Comité de Basilea introducirá unos estándares mínimos para el riesgo de liquidez armonizados internacionalmente. En este sentido, ha desarrollado dos instrumentos reguladores para perseguir objetivos separados pero complementarios. El coeficiente de cobertura de liquidez (LCR) identifica aquellos activos líquidos que pueden utilizarse para compensar salidas de efectivo netas bajo escenarios de tensión definidos por los supervisores. El coeficiente de financiación estable neta (NSFR) abarca todo el balance del banco a partir de una estimación de fuentes de financiación fiables en situaciones de tensión más agudas y prolongadas que el coeficiente de cobertura de liquidez.

Tras un periodo de observación que comenzará en 2011 , el coeficiente de cobertura de liquidez entrará en vigor formalmente el 1 de enero de 2015. Por su parte, el coeficiente de financiación estable neta revisado se convertirá en estándar mínimo el 1 de enero de 2018. El Comité pondrá en marcha una rigurosa vigilancia sobre estos coeficientes durante el periodo de transición y seguirá analizando sus implicaciones para los mercados financieros, la concesión de crédito y el crecimiento económico, atendiendo cualquier efecto secundario indeseado cuando sea necesario. 


\section{Novedades de Basilea III respecto Basilea II}

Basilea III supone un refuerzo fundamental, y en algunos casos un cambio radical, de las normas internacionales de capital.

Las nuevas normas redundarán en un incremento significativo de la capitalización del sector bancario mundial. Siempre que la transición se lleve a cabo correctamente, estas normas más rigurosas reportarán beneficios desde el primer día de su implementación.

Como ilustración, consideremos los tres elementos que componen los requerimientos mínimos del capital: el numerador (la medida del capital), el denominador (la medida de los activos cuyas pérdidas absorbería el capital) y el coeficiente en sí mismo. Estos tres elementos han sido reforzados con las nuevas normas acordadas por los Gobernadores y Jefes de Supervisión de los 27 países que componen el Comité de Basilea.

En cuanto al numerador, el Comité ha reforzado el capital ordinario, también llamado básico, que es el que más pérdidas absorbe. El resultado es una definición mucho más estricta de lo que puede considerarse capital ordinario. La estructura de capital también se ha armonizado y simplificado con criterios de admisión más estrictos para el capital de Nivel 1 y Nivel 2.

\section{TABLA I. Comparación de Basilea II y Basilea III en cuanto a requerimientos de capital}

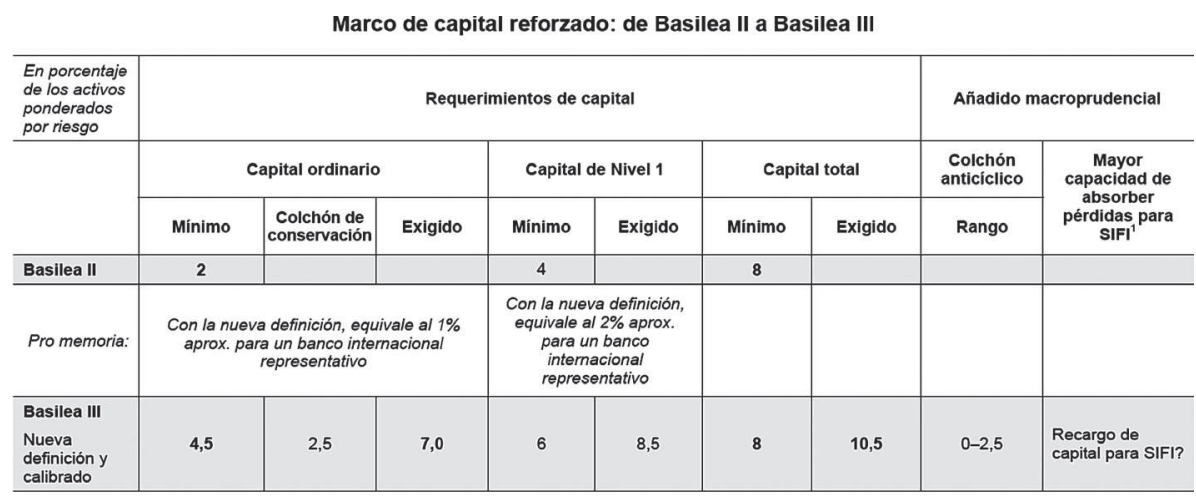

Fuente: Banco de Pagos Internacionales, J. CARUANA (2010) "Basilea III: hacia un sistema financiero más seguro", $3^{a}$ Conferencia Internacional de Banca, Madrid, 15 de septiembre de 2010. 
En cuanto al denominador, el Comité ha adoptado una serie de medidas para que el nuevo marco regulador cubra toda la gama de riesgos significativos. Un nivel de capital adecuado sólo puede proteger frente a pérdidas inesperadas siempre que todos los riesgos estén adecuadamente cubiertos. Durante la crisis, el capital que respaldaba las exposiciones de la cartera de negociación bancaria era a todas luces inadecuado. Como respuesta, el Comité ha endurecido las normas que rigen esta cartera para tener en cuenta el riesgo de crédito de operaciones complejas y con derivados, de forma que al ponderarse con un mayor coeficiente, las exigencias de capital aumentan.

También ha elevado los requerimientos de capital para posiciones de retitulización y está ultimando nuevas normas sobre el riesgo de crédito de contraparte para hacer más fuertes a los bancos individuales y reducir el riesgo de contagio entre instituciones a través de los derivados y del canal de financiación.

En tercer y último lugar, en lo que respecta al propio coeficiente de capital, como hemos visto un componente esencial de Basilea III es un aumento significativo del requerimiento mínimo de capital ordinario o básico hasta el $4,5 \%$, frente al requerimiento actual del $2 \%$. Pero a tenor de los cambios en la definición que se han mencionado, la diferencia en realidad es mayor de lo que estas dos magnitudes hace pensar. El abandono de la antigua definición de capital más permisiva en favor de una nueva definición más estricta reduce a la mitad el capital admisible existente para cumplir los requerimientos. La crisis ha demostrado la importancia de crear "colchones" de capital durante los buenos momentos para disponer de ellos en los momentos de tensión. Por ello, como ya se ha visto más arriba, el Comité de Basilea defiende la creación de un colchón de conservación de capital, que se fijaría en el 2,5\% y estaría compuesto de capital ordinario. Sumado al 4,5\% exigido como requerimiento mínimo de capital, la ratio total alcanzaría el 7\%.

El Comité también ha acordado (como ya se ha comentado) la creación de un colchón anticíclico que elevaría el de conservación de capital en 2,5 puntos porcentuales durante periodos de crecimiento excesivo del crédito.

Para poner estas cifras en perspectiva $(4,5 \%$ de requerimiento mínimo, más $2,5 \%$ de colchón de conservación, más $2,5 \%$ de colchón anticíclico), observemos que durante las crisis más recientes que las pérdidas sufridas por los grandes bancos con actividad internacional en el percentil 99 oscilaron entre el $4 \%$ y el $5 \%$ de sus activos ponderados por riesgo. Es decir, el $99 \%$ de las pérdidas registradas fueron del $5 \%$ o menos de los activos ponderados por riesgo. 


\section{TABLA 2. Disposiciones transitorias de los distintos coeficientes, deducciones y colchones de capital}

\begin{tabular}{|c|c|c|c|c|c|c|c|c|c|}
\hline & 2011 & 2012 & 2013 & 2014 & 2015 & 2016 & 2017 & 2018 & 1 enero 2019 \\
\hline Coeficiente de apalancamiento & \multicolumn{2}{|c|}{$\begin{array}{l}\text { Periodo de } \\
\text { seguimiento } \\
\text { supervisor }\end{array}$} & \multicolumn{4}{|c|}{$\begin{array}{l}\text { Periodo de aplicación en paralelo } \\
1 \text { ene 2013-1 enero } 2017 \\
\text { Comienzo de divulgación } 1 \text { enero } 2015\end{array}$} & & $\begin{array}{c}\text { Trasposición } \\
\text { al Pilar I }\end{array}$ & \\
\hline Coeficiente minimo de capital ordinario & & & $3,5 \%$ & $4,0 \%$ & $4,5 \%$ & $4,5 \%$ & $4,5 \%$ & $4,5 \%$ & $4,5 \%$ \\
\hline Colchón de conservación del capital & & & & & & $0,625 \%$ & $1,25 \%$ & $1,875 \%$ & $2,50 \%$ \\
\hline $\begin{array}{l}\text { Coeficiente minimo de capital ordinario más } \\
\text { colchón de conservación del capital }\end{array}$ & & & $3,5 \%$ & $4,0 \%$ & $4.5 \%$ & $5,125 \%$ & $5,75 \%$ & $6,375 \%$ & $7,0 \%$ \\
\hline $\begin{array}{l}\text { Deducciones sobre el capital ordinario de } \\
\text { Nivel } 1 \text { (incluyendo importes por encima } \\
\text { del limite para DTAs, MSRs y financieras) }\end{array}$ & & & & $20 \%$ & $40 \%$ & $60 \%$ & $80 \%$ & $100 \%$ & $100 \%$ \\
\hline Coeficiente minimo de capital de Nivel 1 & & & $4,5 \%$ & $5,5 \%$ & $6,0 \%$ & $6,0 \%$ & $6,0 \%$ & $6,0 \%$ & $6,0 \%$ \\
\hline Coeficiente mínimo de capital total & & & $8,0 \%$ & $8,0 \%$ & $8,0 \%$ & $8,0 \%$ & $8,0 \%$ & $8,0 \%$ & $8,0 \%$ \\
\hline $\begin{array}{l}\text { Coeficiente mínimo de capital total más } \\
\text { colchón de conservación }\end{array}$ & & & $8,0 \%$ & $8,0 \%$ & $8,0 \%$ & $8,625 \%$ & $9,25 \%$ & $9,875 \%$ & $10,5 \%$ \\
\hline $\begin{array}{l}\text { Instrumentos que dejan de admitirse como } \\
\text { capital de Nivel } 1 \text { no ordinario o de Nivel } 2\end{array}$ & & & \multicolumn{7}{|c|}{ Eliminación progresiva a lo largo de un horizonte de 10 años a partir de 2013} \\
\hline $\begin{array}{l}\text { Coeficiente de cobertura de liquidez (a } \\
\text { corto plazo) }\end{array}$ & \begin{tabular}{|c|} 
Inicio \\
periodo de \\
observación
\end{tabular} & & & & $\begin{array}{l}\text { Introducción } \\
\text { estándares } \\
\text { minimos }\end{array}$ & & & & \\
\hline $\begin{array}{l}\text { Coeficiente de financiación estable neta (a } \\
\text { largo plazo) }\end{array}$ & & \begin{tabular}{|c|} 
Inicio \\
periodo de \\
observación
\end{tabular} & & & & & & $\begin{array}{c}\text { Introducción } \\
\text { estándares } \\
\text { minimos }\end{array}$ & \\
\hline
\end{tabular}

Fuente: COMITÉ DE SUPERVISIÓN BANCARIA DE BASILEA, Comunicado de prensa (2010)”El Grupo de Gobernadores y Jefes de Supervisión alcanzan un amplio acuerdo en torno al paquete de reformas del Comité de Basilea sobre el capital y liquidez".

\section{El nuevo Real Decreto 2/20 I I}

\section{I. Explicación del contenido}

El sistema bancario español soportó razonablemente bien la primera fase de la crisis que estalló en el verano de 2007, ya que ni intermedió en la comercialización ni invirtió en productos crediticios complejos o "tóxicos" en grandes cantidades. El régimen de regulación y supervisión bancaria aplicado en España también ayudó a atenuar el impacto de la crisis financiera internacional.

No obstante, durante la larga etapa de expansión económica precedente, el sistema bancario español había acumulado algunos desequilibrios, ya que tanto la capacidad instalada como el crédito, sobre todo el concedido al sector de promoción y construcción inmobiliaria, habían crecido a ritmos difícilmente sostenibles a medio y largo plazo. Además, esta expansión se financió en buena parte acudiendo a los 
mercados de renta fija internacionales, ya que los depósitos captados a las familias y empresas españolas no eran suficientes para sostener un ritmo de crecimiento del crédito tan intenso.

Hay que señalar que no todas las entidades se vieron afectadas en la misma medida por una crisis tan prolongada como la actual que, además, se trasladó a la economía real. De hecho, los efectos se han concentrado sobre todo en una parte de las Cajas de Ahorros, que fueron las que acumularon los desequilibrios con mayor intensidad.

Las Cajas de Ahorros han vivido en los últimos meses un fuerte proceso de concentración, pasando de 45 a 15 entidades o grupos, con el objetivo de mejorar su eficiencia mediante la reducción de su capacidad instalada. En paralelo, las entidades de crédito han realizado un ejercicio de máxima transparencia, desvelando todos los datos sobre su situación real y sus riesgos (en particular la exposición inmobiliaria y la dependencia de la financiación mayorista), y han abordado un saneamiento intenso de sus activos más problemáticos.

Este esfuerzo considerable para superar los desequilibrios acumulados ha contrastado, sin embargo, con las dudas e incertidumbres sobre el sector que han seguido latentes en los mercados financieros. El pasado mes de noviembre de 2010 la desconfianza de los mercados en la fortaleza del sistema financiero español se vio agravada con el segundo episodio de la crisis de deuda soberana, que afectó sobre todo a Irlanda, pero cuyos efectos se contagiaron a otras economías de la eurozona.

El deterioro de la confianza y las consiguientes dificultades para obtener financiación en los mercados internacionales hacían necesaria la adopción de nuevas medidas que permitieran asegurar la culminación de los avances ya realizados en el último año y medio en la reestructuración de Cajas de Ahorros, con medidas como la creación del FROB (Fondo de Reestructuración Ordenada Bancaria) en el verano de 2009, y la publicación de los resultados de las pruebas de resistencia y la reforma de la ley de cajas en julio de 2010. Las nuevas medidas intentan acelerar y profundizar los cambios que ya se han realizado.

La primera de las nuevas medidas adoptadas fue el requerimiento realizado por el Banco de España el pasado mes de noviembre de un esfuerzo adicional de transparencia a las entidades de crédito, mediante la publicación de datos detallados e individualizados sobre los riesgos con el sector de promoción y construcción inmobiliaria, que se ha realizado en los últimos días de enero de 2011. 
Además, el Gobierno ha decidido dar un paso más con la aprobación el día 18 de febrero de 2011 de un Real Decreto-ley que garantizará la mejora de los niveles de solvencia no sólo de las Cajas de Ahorros sino de todo el sistema financiero, propiciando la obtención de capital por parte de aquellas entidades que lo necesiten, ya sea en el mercado o, cuando esto no sea temporalmente posible, a través de los recursos del FROB. De esta manera se pretende despejar cualquier duda que pudiera persistir sobre la fortaleza del sistema financiero español, de tal forma que pueda seguir atendiendo la demanda solvente de crédito de familias y empresas.

\subsection{Objetivos}

Los objetivos fundamentales del Real Decreto-Ley $2 / 2011^{16}$ de 18 de febrero para el reforzamiento del sistema financiero son tres:

a) Elevar el grado de capitalización de las entidades para mejorar su acceso a la financiación y, en general, para reforzar la confianza en la solidez del sistema bancario español.

b) Incentivar a las entidades para que acudan a los mercados de capitales y para que adopten estructuras fáciles de comprender y evaluar por parte de los mercados.

c) Acelerar la reestructuración de acuerdo con las normas de competencia comunitarias.

Desde el momento de la entrada en vigor del Real Decreto-ley (en adelante RDL), las entidades españolas deben mantener como mínimo unos recursos propios ("Core capital") del $8 \%$ (10\% en el caso de las entidades con mayor dependencia de los mercados mayoristas y que no han demostrado capacidad para acceder al mercado de capitales). El concepto de "capital Core" según el RD es distinto del concepto de capital básico definido en Basilea III, a continuación se especifica la diferencia entre ambos.

- El RDL 2/2011 habla de capital básico ("Core Capital") mientras que Basilea III lo denomina "Common Equity".

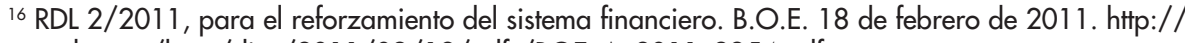
www.boe.es/boe /dias/2011/02/19/pdfs/BOE-A-2011-3254.pdf 
- En cuanto a las partidas que se incluyen en la definición de capital, reservas y primas de emisión son similares.

- Las participaciones representativas de intereses minoritarios en el Real DecretoLey se incluyen como capital en el 100\%, mientras que en Basilea III se incluyen parcialmente.

- Los instrumentos suscritos por el FROB, los instrumentos obligatoriamente transformables en acciones y los ajustes positivos por valoración de activos financieros disponibles para la venta netos de efectos fiscales se incluyen en el sumando del RDL, mientras que Basilea III no hace referencia a ellos.

- Los resultados negativos y las pérdidas aparecen en el RDL como partidas que disminuyen los recursos propios (aparecen restando), mientras que Basilea III da por hecho que una entidad financiera o de depósito no puede tener pérdidas.

- Basilea III detalla exhaustivamente lo que se incluye o no en las partidas de inversiones de capital en instituciones financieras, el RDL no hace referencia a los mismos.

- El fondo de comercio y los activos intangibles son similares en Basilea IIl y el RDL.

Para resumir los aspectos más importantes, en la tabla 3 a continuación se vuelven a exponer las diferencias y similitudes entre "Core capital" y "Common Equity"

\subsection{Exigencia de nuevos requisitos de capital}

A la estela de Basilea III, el Gobierno de España a través de su Ministerio de Economía y Hacienda sigue la estrategia de reformular el contenido del "Capital Básico" o "Core Capital", así como de elevar los niveles de exigencia. Los nuevos requerimientos de capital son:

1. Se exige a las entidades una ratio de capital de la máxima calidad (capital core) de, al menos, un $8 \%$

a) Se aproxima la definición de capital core de Basilea III-2013,...

b) ... endureciendo muy significativamente el requisito mínimo.

c) Dicho endurecimiento no está sujeto a juicio de valor: dependerá de (1) la posición de partida y (2) el requisito mínimo de capital. 


\section{TABLA 3. Comparación Core Capital/capital básico RD 2/20I I vs Common Equity Basilea III}

\begin{tabular}{|c|c|c|c|}
\hline & $\begin{array}{c}\text { Capital Básico/"Core } \\
\text { Capital" } \\
\text { Ministerio de Economía }\end{array}$ & $\begin{array}{c}\text { Capital Básico Basilea III } \\
\text { "Common Equity" + } \\
\text { ajustes }\end{array}$ & Diferencias \\
\hline \multirow{7}{*}{ Suman } & \multirow{2}{*}{$\begin{array}{l}\text { Capital social de sociedades anóni- } \\
\text { mas, fondos fundacionales y cuotas } \\
\text { participativas de cajas de ahorro y } \\
\text { cuotas participativas de asociación } \\
\text { emitidas por la CECA; aportaciones } \\
\text { al capital social de las cooperativas } \\
\text { de crédito; reservas y resultados posi- } \\
\text { tivos de ejercicios computables. }\end{array}$} & $\begin{array}{l}\text { Acciones ordinarias (o su equiva- } \\
\text { lente para las compañías que no } \\
\text { son sociedades anónimas) }\end{array}$ & Similares \\
\hline & & Reservas & Similares \\
\hline & Primas de emisión & Primas de emisión & Similares \\
\hline & $\begin{array}{l}\text { Participaciones representativas de } \\
\text { intereses minoritarios }\end{array}$ & $\begin{array}{l}\text { Se admite la inclusión parcial de } \\
\text { intereses minoritarios en filiales } \\
\text { bancarias }\end{array}$ & $\begin{array}{l}\text { Inclusión } \\
\text { parcial }\end{array}$ \\
\hline & Instrumentos suscritos por el FROB & & $\begin{array}{l}\text { Basilea III no } \\
\text { se define }\end{array}$ \\
\hline & $\begin{array}{l}\text { Instrumentos obligatoriamente trans- } \\
\text { formables en acciones }\end{array}$ & & $\begin{array}{l}\text { Basilea III no } \\
\text { se define }\end{array}$ \\
\hline & $\begin{array}{l}\text { Ajustes positivos por valoración de } \\
\text { activos financieros disponibles para } \\
\text { la venta neto de efectos fiscales }\end{array}$ & & $\begin{array}{l}\text { Basilea III no } \\
\text { se define }\end{array}$ \\
\hline \multirow[t]{3}{*}{ Restan } & (Resultados negativos y pérdidas) & $\begin{array}{l}\text { - (Inversiones de capital en institu- } \\
\text { ciones financieras, la deducción } \\
\text { será total si las entidades son } \\
\text { del grupo o si existen acuerdos } \\
\text { de inversión recíproca) } \\
\text { - (activos fiscales diferidos por } \\
\text { diferencias temporales) } \\
\text { - (inversiones financieras en } \\
\text { entidades financieras que no } \\
\text { consoliden) } \\
\text { - (los derechos de servicio de } \\
\text { hipotecas) }\end{array}$ & $\begin{array}{l}\text { Ministerio no } \\
\text { se define }\end{array}$ \\
\hline & $\begin{array}{l}\text { (Activos inmateriales, incluido el } \\
\text { fondo de comercio procedente de } \\
\text { combinaciones de negocio, de } \\
\text { consolidación o de la aplicación del } \\
\text { método de la participación) }\end{array}$ & \multirow[t]{2}{*}{$\begin{array}{l}\text { (Fondo de Comercio y otros } \\
\text { Activos Intangibles) }\end{array}$} & \multirow[t]{2}{*}{ Similares } \\
\hline & $\begin{array}{l}\text { (Ajustes negativos por valoración de } \\
\text { activos financieros disponibles para } \\
\text { la venta neto de efectos fiscales) }\end{array}$ & & \\
\hline
\end{tabular}

Fuente: Elaboración propia. 
2. La ratio de capital core exigida será del $10 \%$ para aquellas entidades de crédito que reúnan las dos condiciones siguientes ${ }^{17}$ :

a) Tener un coeficiente de financiación mayorista superior al $20 \%$.

b) No haber colocado a terceros títulos representativos de su capital social o derechos de voto por un porcentaje igual o superior al $20 \%$ del mismo.

3. El FROB actúa como "backstop" (apoyo/respaldo) desde la aprobación del Real Decreto-ley, lo que en la práctica, implica que:

a) Las entidades que no puedan obtener capital en el mercado acudirán al FROB.

b) Desde la publicación del Real Decreto-ley, las entidades españolas deben operar con un "core equity capital" de, al menos, un $8 \%$.

Cuando coyunturalmente una entidad presente un nivel de capital principal inferior al mínimo establecido en los apartados anteriores y este nivel de insuficiencia sea menor a un $20 \%$ del mínimo exigido, el Banco de España impondrá restricciones que podrán afectar al reparto de dividendos, la dotación a la obra benéficosocial, las remuneraciones variables de administradores y directivos, la retribución de las participaciones preferentes y la recompra de acciones. En todo caso, las restricciones previstas en este apartado dejarán de ser de aplicación a partir de la incoación de un expediente sancionador.

El Banco de España podrá exigir a las entidades el cumplimiento de un nivel de capital principal superior al previsto (8\%-10\%) si la entidad no alcanza, en el escenario más adverso de una prueba de resistencia del conjunto del sistema, el nivel de recursos propios mínimos exigido en dicha prueba y hasta el límite de dicha exigencia.

Los fondos aportados por el FROB formarán parte de "Core capital" de las entidades financieras, restableciendo de este modo el capital necesario para el cumplimiento de los nuevos requerimientos de capital por parte del Ministerio de Economía y Hacienda. Estos fondos se aportarán mediante la adquisición de acciones ordinarias. En el caso de cajas de ahorros, puesto que carecen de capital social, si tienen la necesidad de acudir al FROB, tienen que traspasar su actividad a un banco, a cuyo capital se incorporarán dichos fondos. De esta forma, en el consejo de administración de ese banco aparecerá un administrador especial representando

${ }^{17}$ Se entiende que la concurrencia de ambas supone mayor riesgo. 
al capital adquirido mediante el FROB. Éste nombrará a la persona o personas físicas que ostenten su representación a tal efecto y dispondrá en el órgano de administración de tantos votos como los que resulten de aplicar al número total de votos su porcentaje de participación en la entidad.

El Fondo de Reestructuración Ordenada Bancaria podrá igualmente adquirir títulos que consistirán en participaciones preferentes convertibles en aportaciones al capital social de las cooperativas de crédito, emitidos por aquellas entidades que, sin incurrir en las circunstancias establecidas en el artículo 6 del presente real decreto-ley, necesiten reforzar sus recursos propios con el fin exclusivo de llevar a cabo entre sí procesos de integración y así lo soliciten.

La suscripción de tales títulos por el Fondo de Reestructuración Ordenada Bancaria vendrá condicionada por la elaboración por las entidades de un plan de integración que deberá detallar las medidas y compromisos específicos dirigidos a conseguir dicho objetivo y que deberá ser aprobado por el Banco de España, bajo el principio de la utilización más eficiente de los recursos públicos. La citada adquisición deberá llevarse a efecto teniendo en cuenta, en todo caso, el plazo y riesgo de la operación, la necesidad de evitar el riesgo de una distorsión competitiva así como que tal adquisición facilite la ejecución y cumplimiento del plan de integración y estará presidida por el principio de la utilización más eficiente de los recursos públicos.

En cuanto al plan de integración, deberá recoger entre otros aspectos, las medidas destinadas a la mejora de la eficiencia, la racionalización de la administración y gerencia, así como decisiones encaminadas al redimensionamiento de la capacidad productiva de la entidad y todo ello con la finalidad de mejorar sus perspectivas futuras. Por tanto, este plan obliga a replantear la estrategia de expansión desmedida (sobredimensionadas) de años atrás que ha puesto en peligro la rentabilidad de las entidades. Asociado a esta racionalización de la estructura dimensional de las entidades está el cierre de las oficinas que estén en pérdidas, que supongan duplicidad de oficinas en la fusión y un plan de prejubilizaciones de los empleados con mayor antigüedad (suponen mayor coste de sueldos y salarios).

En lo relativo a los valores emitidos (participaciones preferentes ${ }^{18}$ ), se regirán por las disposiciones contenidas en la disposición adicional segunda de la Ley

\footnotetext{
${ }^{18}$ Aunque no se relaciona directamente con el tema tratado en este artículo, no podemos dejar de mencionar los problemas que se han producido en España como consecuencia del empleo de estos títulos por parte de las entidades de nuestro país.
} 
13/1985, de 25 de mayo ${ }^{19}$, sobre coeficientes de inversión, recursos propios y obligaciones de información de los intermediarios financieros, si bien tendrán ciertas especialidades, recogidas a continuación.

a) La emisión tendrá carácter excepcional y sólo podrá acordarse al amparo y a efectos de lo dispuesto en este RDL 2/2011, para el reforzamiento del sistema financiero. Las entidades emisoras deberán aprobar, en el momento de la adopción del acuerdo de emisión de las participaciones preferentes, los acuerdos necesarios para la suscripción de aportaciones al capital en la cuantía necesaria. Los términos y condiciones de la retribución de las participaciones preferentes tendrán en cuenta, en todo caso, los principios que se establezcan por la Comisión Europea.

b) Las entidades emisoras deberán comprometerse a recomprar los títulos suscritos por el Fondo de Reestructuración Ordenada Bancaria tan pronto como estén en condiciones de hacerlo en los términos comprometidos en el plan de integración. Transcurridos cinco años desde el desembolso sin que las participaciones preferentes hayan sido recompradas por la entidad, el Fondo de Reestructuración Ordenada Bancaria podrá solicitar su conversión en aportaciones sociales emitidas por el emisor. El ejercicio de esta facultad deberá realizarse, en su caso, en el plazo máximo de 6 meses contados a partir de la finalización del quinto año desde que se produjo el desembolso de las participaciones preferentes.

${ }_{19}$ Segunda-Las Entidades de depósito y otras privadas distintas de las reguladas por la Ley 33/1984, de 2 de agosto, sobre ordenación del seguro privado, en cuyos Estatutos se hubiese autorizado, con anterioridad a la entrada en vigor de la presente Ley, la posibilidad de efectuar operaciones de seguros diferentes de las de la Seguridad Social obligatoria, no podrán ampliar su actividad a nuevas modalidades de seguros y quedarán sometidas a las siguientes normas:

a) No estarán sujetas, en cuanto a las operaciones de seguros, a los coeficientes de caja e inversión y cualquier otro típico de sus actividades como Entidades de deposito.

b) Deberán llevar las operaciones de seguro con absoluta separación contable y económico-financiera respecto del resto de las operaciones que realicen. Asimismo, dentro del plazo de dos años a partir de la entrada en vigor. de la presente Ley, deberán contar con un patrimonio afecto exclusivamente a las operaciones de seguros, el cual estará jurídicamente separado de los demás elementos patrimoniales de la Entidad y responderá sólo de las resultas de tales operaciones de aseguramiento, sin que tampoco puedan estas últimas recaer jurídicamente sobre el restante patrimonio de la Entidad.

c) Les serán de plena aplicación las normas específicas reguladoras de las operaciones de seguros y de la actividad aseguradora con excepción de lo relativo a la denominación y objeto social y al régimen de Estatutos de la Entidad, si bien no podrán en ningún caso ser cesionarias en todo o en parte de carteras de seguros, a partir de la entrada en vigor de la presente Ley 
No obstante lo anterior, el acuerdo de emisión deberá contemplar asimismo la convertibilidad de las participaciones preferentes a instancias del Fondo de Reestructuración Ordenada Bancaria si, antes del transcurso del plazo de cinco años, el Banco de España considera improbable, a la vista de la situación de la entidad o su grupo, que la recompra de las participaciones preferentes pueda llevarse a cabo en ese plazo.

c) Las participaciones preferentes emitidas al amparo de lo dispuesto en este precepto serán computables como recursos propios básicos, sin que para ello sea obligatorio que coticen en un mercado secundario organizado. A estos efectos, no les serán de aplicación las limitaciones que la ley establece para la computabilidad de los recursos propios.

d) El acuerdo de emisión de estos títulos deberá ajustarse, asimismo, a las restantes condiciones comprometidas en el plan de integración.

Con esta medida asistimos a una trasformación radical del Sistema Financiero Español, "nacionalizando" en parte entidades financieras, que a medio plazo no iban a poder cumplir los nuevos requerimientos de capital de Basilea III. Esta nacionalización es temporal, ya que el FROB venderá los títulos que haya adquirido en un plazo no superior a los cinco años a contar desde la fecha de su suscripción. Si la entidad que acudió al FROB ha generado los beneficios y las reservas suficientes para adquirir los títulos, recuperarán y mantendrá el control en el consejo de administración, de lo contrario inversores privados con capital nacional o internacional entrarán a formar parte de la entidad y por consiguiente del consejo de administración.

\subsection{Comparación con Basilea III}

Como ya se ha indicado, el Real Decreto Ley nace con el objeto de anticipar una década los nuevos requerimientos de capital de Basilea III, pero se centra específicamente en la calidad y cuantía del capital. Por otra parte, Basilea III define nuevos instrumentos de control sobre las entidades financieras como son el coeficiente de apalancamiento, coeficiente de cobertura de liquidez a corto plazo y el coeficiente de financiación estable neta a largo plazo. Además tiene en cuenta la un colchón de capital anticíclico con un rango de aplicación de 0-2,5\% según el caso y un recargo de capital aún por determinar, a las instituciones financieras de importancia sistémicas (SIFIs). En consecuencia, para realizar una comparación correcta entre ambas normativas, no sólo hay que ver las diferencias entre el el 
capital básico en el RDL y Basilea III, sino además tener en cuenta el colchón anticíclico y realizar una simulación de su aplicación a instituciones financieras de importancia sistémica.

\section{Requerimientos de core capital bajo la nueva regulación española y comparación con los requerimientos de Basilea III}

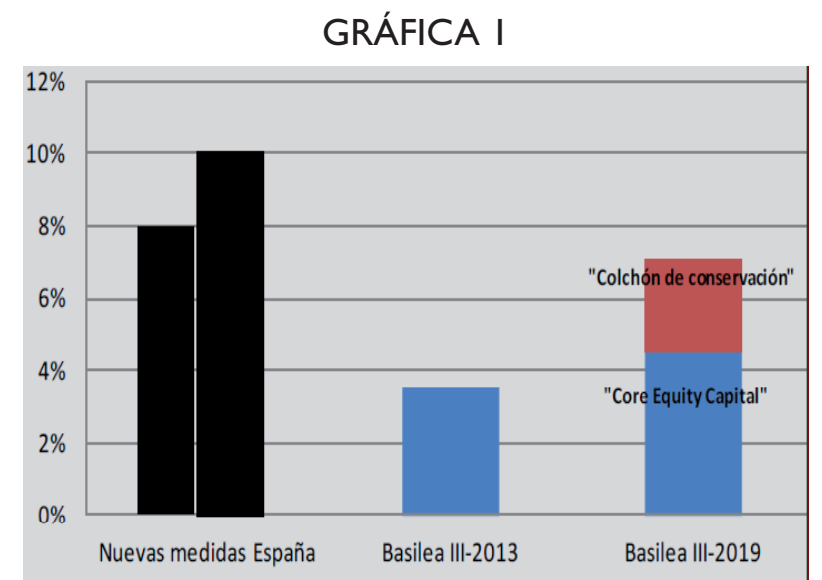

GRÁFICA 2. RDL 2/201। vs Basilea III

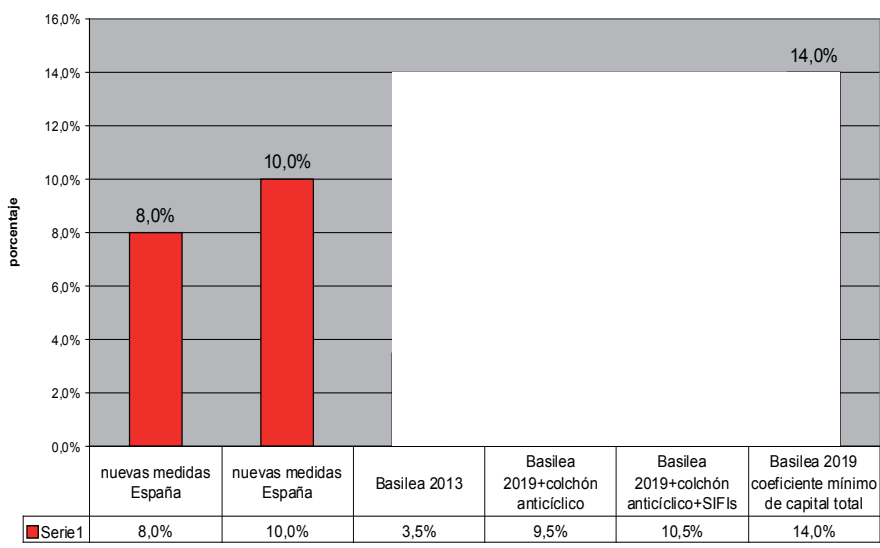

Fuente: Elaboración propia.

Fuente: Banco de España. FERNÁNDEZ, M. (2011) "La reestructuración del sector bancario español y el Real Decreto-ley para el reforzamiento del sistema". 


\subsection{Efectos de las nuevas normas en las Cajas de Ahorros}

El objetivo de este epígrafe es observar la incidencia de las medidas analizadas en los apartados anteriores sobre un grupo de entidades financieras: las cajas de ahorros.

Analizando los datos de las memorias anuales y de la "información de relevancia prudencial" que las Cajas de Ahorros están obligadas a presentar al Banco de España, se ha calculado el porcentaje de "Core Capital" como el cociente entre el importe de capital básico publicado por el Banco de España ${ }^{20}$ en marzo de 2011 y los activos ponderados al riesgo publicado por cada Caja de Ahorros en sus informes respectivos del año $2009^{21}$.

\section{TABLA 4. Relación de "Core Capital” de las cajas de ahorros, cumplimiento y requerimiento del Ministerio de Economía}

\begin{tabular}{|c|c|c|c|c|c|c|}
\hline & \multicolumn{5}{|c|}{ DATOS A MARZO DE 2011} \\
\hline & & $\begin{array}{l}\text { Core } \\
\text { capital }\end{array}$ & $\begin{array}{c}\text { Requerimiento } \\
\text { Basilea III (Core } \\
\text { Capital +/- } \\
\text { ajustes) 2013 }\end{array}$ & $\begin{array}{l}\text { Requerimiento } \\
\text { Basilea III (Core } \\
\text { Capital +/- } \\
\text { ajustes) } 2019\end{array}$ & $\begin{array}{c}\text { Requerimiento } \\
\text { Ministerio Economía } \\
\text { (Core Capital } \\
\text { +/- ajustes) }\end{array}$ & Cumplimiento \\
\hline \multirow{17}{*}{ 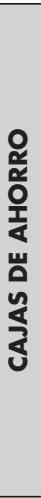 } & Grupo BMN (Mare Nostrum) & 8,2 & 3,50 & 7,00 & 10,00 & No cumple \\
\hline & Banca Cívica & 8,10 & 3,50 & 7,00 & 10,00 & No cumple \\
\hline & Unicaja+Caja de Jaén & 13,10 & 3,50 & 7,00 & 10,00 & Cumple \\
\hline & Caixa & 9,90 & 3,50 & 7,00 & 8,00 & Cumple \\
\hline & Bankia & 7,10 & 3,50 & 7,00 & 10,00 & No cumple \\
\hline & BBK (incluye CajaSur) & 12,30 & 3,50 & 7,00 & 10,00 & Cumple \\
\hline & Catalunyacaixa & 6,50 & 3,50 & 7,00 & 10,00 & No cumple \\
\hline & Novacaixagalicia & 5,20 & 3,50 & 7,00 & 10,00 & No cumple \\
\hline & Ibercaja & 9,98 & 3,50 & 7,00 & 8,00 & Cumple \\
\hline & Caja España de Inversiones & 8,20 & 3,50 & 7,00 & 10,00 & No cumple \\
\hline & Kutxa & 12,50 & 3,50 & 7,00 & 10,00 & Cumple \\
\hline & Caja 3 & 8,85 & 3,50 & 7,00 & 8,00 & Cumple \\
\hline & Unnim & 7,10 & 3,50 & 7,00 & 10,00 & No cumple \\
\hline & Base disuelta (CAM) & 8,20 & 3,50 & 7,00 & 10,00 & No cumple \\
\hline & Vital & 12,50 & 3,50 & 7,00 & 8,00 & Cumple \\
\hline & Ontinyent & 8,80 & 3,50 & 7,00 & 8,00 & Cumple \\
\hline & Pollensa & 10,59 & 3,50 & 7,00 & 8,00 & Cumple \\
\hline
\end{tabular}

Fuente: Banco de España. Nota informativa, (201 1) "El Banco de España comunica a 12 entidades que deben aumentar su capital para cumplir con el Real Decreto-ley" y elaboración propia.

20 El Banco de España comunica a 12 entidades que deben aumentar su capital para cumplir con el Real Decreto-ley. BANCO DE ESPAÑA. Nota informativa, (2011) "El Banco de España comunica a 12 entidades que deben aumentar su capital para cumplir con el Real Decreto-ley". Madrid. http://www. bde.es/webbde/es/secciones/prensa /Notas_Informativ/anoactual/presbe2011_9.pdf

${ }^{21}$ Éste era el último dato disponible en la fecha de elaboración de este artículo. 
De los datos obtenidos de las entidades de depósito y el Banco de España observamos que seis cajas de ahorros no cumplían los nuevos requisitos de capital del RDL 2/201 1: el grupo Banco Mare Nostrum, Banca Cívica, Bankia, Catalunyacaixa, Novacaixa Galicia, Caja España de Inversiones (actualmente en proceso de fusión con Unicaja), UNNIM y Banco Base (éste actualmente ha acordado su disolución debido a los problemas de solvencia de la CAM que afectaban al grupo completo). Los efectos que conlleva el incumplimiento y las opciones que tenían las entidades antes de acudir al FROB las vemos a continuación.

Las entidades financieras afectadas por los nuevos requerimientos de capital del Real Decreto Ley $2 / 2011$ se verían sometidas a las restricciones descritas anteriormente, de las que destacan el reparto de dividendos, la dotación a la obra benéfico-social y la remuneración a administradores y directivos. En situaciones puntuales de tensiones de solvencia una entidad podía presentar un nivel de capital principal inferior al $8 \%-10 \%$ y si este nivel de insuficiencia era menor a un $20 \%$ del mínimo exigido, el Banco de España impondrá las restricciones que describimos con anterioridad. El Banco de España realizó pruebas de tensión ("stress testing"), que podían conllevar niveles superiores de requerimientos de capital adicionales para las entidades que no los cumplan ${ }^{22}$. Como ya se ha indicado, las cajas de ahorros que tuvieran la necesidad de acudir al FROB, debían traspasar su actividad a un banco, a cuyo consejo de administración se incorporaría un administrador especial representando al capital adquirido mediante el FROB.

En los casos de las entidades analizadas, recordemos que Banca Cívica acordó en Consejo de 23 de febrero de 2011 la salida al mercado, debiendo colocar al menos el $20 \%$ de su capital social para evitar la concurrencia de los dos factores que determinan el $10 \%$ en lugar del $8 \%$ de capital básico de los activos ponderados al riesgo. Algo similar sucedió en el grupo Mare Nostrum, que también acordó en Consejo de 23 de febrero de 2011 la salida al mercado para colocar al menos el $20 \%$ de su capital social, lo que le evitaría necesitar capital adicional del FROB.

Unicaja cumplía sobradamente los nuevos requerimientos de capital, pero su volumen de activos (3100 millones) estaba muy lejos del volumen mínimo de activos que recomendaba el Banco de España (50.000 millones). Esto la ponía ante la decisión de buscar nuevas fórmulas de ampliar sus activos sin perder el cumplimiento de requerimiento de capital. Actualmente está en proceso de fusión con Caja España de Inversiones solventando el problema de tamaño.

22 Recordemos que estas pruebas han sido repetidas posteriormente por otras entidades ajenas al supervisor español. 


\subsection{Necesidades de capital}

En el momento inicial de escribir este texto se estimaba que entre todas las Cajas de Ahorros (en curso de integración) necesitarían un importe de 14.077 millones de euros, siendo la totalidad de lo estimado por el Banco de España en toda España para bancos, cajas de ahorros y cooperativas de crédito de 15.152 millones de euros. Por tanto las cajas de ahorros necesitaban el $92,90 \%$ del FROB para sanear las necesidades de capital básico con los nuevos requerimientos descritos en el RDL 2/2011 de reforzamiento de las entidades financieras.

TABLA 5. Necesidades de capital en millones y cumplimiento de las cajas de ahorros españolas

\begin{tabular}{|c|c|c|c|c|c|c|c|}
\hline & \multirow{2}{*}{$\begin{array}{c}\begin{array}{c}\text { Situación de } \\
\text { partida capital } \\
\text { principal }\end{array} \\
\text { (1) } \\
\end{array}$} & \multicolumn{4}{|c|}{ Coeficiente de capital principal } & \\
\hline & & & (2) & (3) & (4) & (5) & \\
\hline & & $\begin{array}{c}\text { Importe en } \\
\text { millones }\end{array}$ & $\begin{array}{l}\text { Nivel a } \\
\text { cumplir por } \\
\text { la entidad } \\
\% \text { (a) }\end{array}$ & Cumplimiento & $\begin{array}{c}\text { Puntos } \\
\text { porcentuales } \\
\text { para llegar al } \\
\text { nivel señalado } \\
\text { en columna (2) }\end{array}$ & $\begin{array}{l}\text { Necesidades de } \\
\text { capital adicional } \\
\text { para alcanzar } \\
\text { nivel señalado en } \\
\text { columna (2) (b) }\end{array}$ & Observaciones \\
\hline \multirow{19}{*}{ 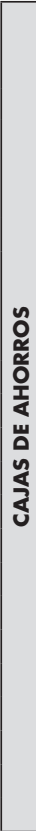 } & \begin{tabular}{|l|} 
GRUPO BMN (MARE \\
NOSTRUM Caja Murcia + \\
Penedés + Caja Granada + \\
Sa Nostra) \\
\end{tabular} & 3.343 & 10,00 & - & 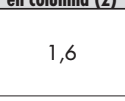 & (civilima $(2)(10)$ & $\begin{array}{l}\text { Acuerdo del Consejo del } 28 \text { de Febrero para } \\
\text { iniciar las gestiones para la salida a Bolsa del } \\
\text { banco. En este caso deberá colocar al menos el } \\
20 \% \text { de su capital social }\end{array}$ \\
\hline & UNICAJA+Caja de JAEN & 2.450 & 10,00 & Cumple & & & \\
\hline & $\begin{array}{l}\text { BANCA CiVICA Cajasol + } \\
\text { Guadalajara + Burgos + } \\
\text { Navarra + Canarias }\end{array}$ & 3.687 & 10,00 & - & 1,9 & 847 & $\begin{array}{l}\text { Acuerdo del consejo de } 23 \text { de febrero de } 2011 \text { de } \\
\text { salida al mercado. En este caso se deberá colocar } \\
\text { al menos el } 20 \% \text { de su capital social. En ese caso } \\
\text { no necesitaría capital adicional del FROB. }\end{array}$ \\
\hline & Caixa & 16.083 & 8,00 & Cumple & & & \\
\hline & Bankia & 14.125 & 10,00 & - & 2,9 & 5.775 & $\begin{array}{l}\text { Acuerdo del Consejo de } 17 \text { de febrero para } \\
\text { iniciar los trámites de salida a bolsa. En ese } \\
\text { caso el importe mínimo adicional para alcanzar } \\
\text { el } 8 \% \text { de capital principal sería de } 1.795 \\
\text { millones de euros. }\end{array}$ \\
\hline & BBK (incluye Caja Sur) & 3.604 & 10,00 & Cumple & & & \\
\hline & Catalunyacaixa & 3.148 & 10,00 & - & 3,5 & 1.718 & \\
\hline & Novacaixagalicia & 2.851 & 10,00 & - & 4,8 & 2.622 & \\
\hline & Ibercaja & 2.425 & 8,00 & Cumple & & & \\
\hline & Unicaja & 2.450 & 10,00 & Cumple & & & \\
\hline & Caja España de Inversiones & 2.062 & 10,00 & - & 1,8 & 463 & \\
\hline & Kutxa & 1.976 & 10,00 & Cumple & & & \\
\hline & Caja 3 & 1.191 & 8,00 & Cumple & & & \\
\hline & Unnim & 1.150 & 10,00 & - & 3,3 & 568 & \\
\hline & Base & 6.582 & 10,00 & - & 1,8 & 1.447 & \\
\hline & Vital & 810 & 8,00 & Cumple & & & \\
\hline & Ontinyent & 57 & 8,00 & Cumple & & & \\
\hline & Pollensa & 20 & 8,00 & Cumple & & & \\
\hline & SUBTOTAL CAJAS & 65.564 & & & & $14.077,00$ & \\
\hline
\end{tabular}

Fuente: Banco de España. Nota informativa, (2011) "El Banco de España comunica a 12 entidades que deben aumentar su capital para cumplir con el Real Decreto-ley" 


\section{Conclusiones}

\section{I.A nivel internacional}

Con Basilea III estamos asistiendo al último paso de la regulación internacional (llámese G20, G10 o G8) para exigir nuevos requerimientos de capital al sistema financiero. La intención del Comité de Supervisión Bancaria de Basilea es limitar los activos que generan riesgo mediante el incremento de capital mínimo de máxima calidad que pueda hacer frente a pérdidas derivadas de dichos riesgos. Estos requisitos, de mantener más capital y activos líquidos para las exposiciones de financiación, incrementarán el coste de forma sustancial para las entidades financieras.

Si Basilea III se lleva a cabo como se propone actualmente, es posible que algunos bancos simplemente sean intervenidos, nacionalizados y vendidos al mejor postor.

$H S B C^{23}$, Standard Chartered ${ }^{24}$ y $R B S^{25}$ han argumentado públicamente que las nuevas normas podrían reducir significativamente el volumen del comercio internacional, resultando en pérdida de empleos y otros costos económicos.

El ratio de apalancamiento, el coeficiente de cobertura de liquidez (LCR) y el coeficiente de financiación estable neta (NSFR) tienen largos períodos de evaluación antes de que la Comisión finalice la implementación. Sin embargo, la Comisión exigirá pruebas empíricas, en lugar de argumentos conceptuales, para revisar el marco general de estos modelos.

El Grupo de Aplicación de Normas tiene la tarea de garantizar una aplicación coherente de Basilea III. La experiencia de Basilea II demuestra el desafío al que

\footnotetext{
${ }^{23}$ Con sede en Londres, HSBC es uno de los mayores bancos y organizaciones de servicios financieros en el mundo. La red internacional de HSBC comprende alrededor de 7,500 oficinas en 87 países y territorios en Europa, la región de Asia y el Pacífico, América, Oriente Medio y África.

${ }^{24}$ Karen Fawcett, la cabeza de la banca de transacción de Standard Chartered, expresó su opinión en una conferencia octubre de 2010: "Si las normas se aplican a medida que se escriben actualmente, podríamos ver una caída de 2 por ciento en el comercio mundial y un 0,5 por ciento caída en el PIB mundial".

25 The Royal Bank of Scotland.
} 
se enfrenta la Comisión en este respecto, y el diálogo constante entre las entidades financieras y la Comisión que se requiere en este frente.

Un reciente estudio realizado por un grupo de trabajo del Comité de Basilea analizó trabajos en la materia para concluir que, en cualquier país, cada 20 a 25 años se produce una crisis financiera seria. En otras palabras, la probabilidad anual media de que acontezca una crisis es del $4 \%-5 \%$ y la pérdida mediana de PIB se estima en torno al $60 \%$ del PIB anual.

Afortunadamente, si analizamos minuciosamente su impacto macroeconómico llegamos a la conclusión de que los costes son moderados, especialmente si las nuevas normas se aplican de forma progresiva a lo largo de un periodo de transición.

Sin embargo, el papel de Basilea III tiene también detractores que consideran lesivo para el negocio bancario el exceso de supervisión que contempla y que, además, podría incrementar indirectamente el "shadow business banking" 26 , segmento del mercado bancario que es difícil de controlar y que ha contribuido de forma determinante al origen de esta crisis.

Desde el punto de vista de la inversión de las empresas, el sistema bancario será más estable y solvente. En contrapartida, la oferta de crédito será presumiblemente menor y más onerosa, ya que, para mantener su margen operativo, los bancos deberán repartir menos dividendos o aumentar los precios de sus productos y servicios.

\subsection{A nivel nacional}

El proceso de reestructuración del sistema financiero español no ha hecho más que empezar y estamos asistiendo a una recapitalización de las entidades financieras y de depósito junto con un saneamiento de sus activos. Las cajas de ahorros tienen una mayor exigencia que los bancos y las cooperativas de crédito. Actualmente, parece que las entidades de depósito más pequeñas son las más solventes y saneadas (por ejemplo así sucede en Andalucía donde las entidades "mejores" son

${ }^{26}$ Existe un fuerte consenso en que el fallo principal que condujo a la actual crisis fue la total desregulación del sistema bancario. Un sistema bancario que en las últimas décadas creó un clon paralelo al de la banca tradicional, plenamente interconectado al sistema financiero global, pero desconectado de la actividad real de la economía. Ese universo paralelo que encontró la industria financiera para llevar a cabo la función tradicional de vincular a los ahorradores con los prestatarios, tuvo un incremento colosal en las últimas décadas. Eso es lo que se conoce como el "sistema bancario en las sombras". 
cajas rurales de carácter local: la Caja Rural de Adamuz con un 24,05\% y la Caja Rural de Nueva Carteya con un 23,85\% de capital básico).

Esto contradice aparentemente lo que predica el Banco de España en cuanto al tamaño mínimo de las entidades, aunque es cierto que pueden tener más dificultades en determinados momentos por la elevada concentración geográfica y por la tipología del negocio volcada en la agricultura. Entre las cajas de ahorros hay grandes diferencias: por ejemplo las mejores tienen ratios superiores al 10\% (Unicaja, BBK, Kutxa y Caja Vital); pero Bankia, Banca Cívica, Grupo BNM, Novacaixagalicia y Catalunyacaixa, necesitan 11.599 millones de euros de capital para cumplir los requerimientos del Banco de España.

En el proceso de reestructuración se ha pasado de 45 a 15 Cajas de Ahorros, algunas en proceso de transformación en Banco, lo que parece indicar que estamos ante el fin del modelo tradicional de Cajas de Ahorros tal y como existía durante el último siglo ${ }^{27}$.

La implementación de los nuevos requerimientos de capital llevará un largo período de estudio, revisión y modificación de las normas que afectan a las entidades financieras a nivel internacional.

27 De hecho, en el momento actual (después de la fecha de elaboración este texto) sólo quedan dos cajas con las características que tenían anteriormente; el resto se han convertido en bancos o han sido adquiridas por éstos, mientras que la obra social de las antiguas cajas ha quedado adscrita a fundaciones independientes de las entidades de depósito. 


\section{Referencias bibliográficas}

ARIZTEGUI, J., (2010) "La reforma del sistema financiero y su supervisión" XIX Congreso Nacional de Auditoría, Madrid.

AspaCHIS, O., (2010) "Basilea III ¿̇a la tercera va la vencida?", Informe mensual La Caixa, número 341 , p 45-47.

Banco Central Europeo (201 la) "Capitulo 4: Estabilidad e integridad financiera". Informe Anual 2010. Frankfurt Alemania.

- (2011b) "Capitulo 6: Tareas relacionadas con la Junta Europea de Riesgo Sistémico" Informe Anual 2010. Frankfurt.

Banco de España (2011a) "El Banco de España comunica a 12 entidades que deben aumentar su capital para cumplir con el Real Decreto-ley", Madrid, http://www.bde.es/webbde/es/secciones/prensa/Notas_Informativ/anoactual/ presbe2011_9.pdf

- (2011 lb) "Evolución y reforma de las Cajas de Ahorros", Madrid, http://www. bde.es/webbde/es/secciones/prensa/reestructura_sane/ficheros/notareformacajas210211.pdf. Madrid.

Banco de Pagos Internacionales (1988) Comité de Supervisión Bancaria de Basilea, "Acuerdo de Capitales" ("International Convergence of Capital Measurement and Capital Standards"), Basilea.

Basel Committee on Banking Supervision, (2010) "Basel III: A global regulatory framework for more resilient banks and banking systems", Basilea. http://www.bis. org/publ/bcbs189.pdf

BULACH, M., (2011) "Prociclicidad de la nueva regulación: ¿Dormiremos más tranquilos con los nuevos colchones?", Informe mensual La Caixa, número 345, p 32-42.

Caruana, J., (2010) "Basilea III: hacia un sistema financiero más seguro", Banco de Pagos Internacionales, $3^{a}$ Conferencia Internacional de Banca, Madrid, 15 de septiembre de 2010.

CECCHETII, S., (2010) "La reforma financiera: progresos hasta ahora" Discurso con motivo del Foro Económico de Westminster, NIESR, Londres, 4 de octubre de 2010 
Comité de supervisión banCARIA de BAsIlEa (2010a), Comunicado de prensa "El Grupo de Gobernadores y Jefes de Supervisión alcanzan un amplio acuerdo en torno al paquete de reformas del Comité de Basilea sobre el capital y liquidez". Basilea. http://www.bis.org/press/p100912_es.pdf

- (2010b), "La respuesta del Comité de Basilea a la crisis Financiera", Basilea. http://www.bis.org/publ/bcbs179_es.pdf

- (2009), "Principios para la realización y supervisión de pruebas de tensión", Basilea. http://www.bis. org/publ/bcbs155_es.pdf

- (2006), "Basilea ll: Convergencia internacional de medidas y normas de capital", Basilea. http://www.bis. org /publ/bcbs128_es.pdf

FERNÁNDEZ, M., (2011) "La reestructuración del sector bancario español y el Real Decreto-ley para el reforzamiento del sistema". http://www.bde.es/webbde /es/ secciones/prensa/intervenpub/gobernador/mfo210211.pdf

Hannoun, H., King, M., Borio, C., McCauley, R., Packer, F., Tissot, B. y Walter, S. (2010), "Hacia un marco de estabilidad financiera", $45^{a}$ Conferencia de Gobernadores de los Bancos Centrales del Sudeste Asiático (SEACEN). http://www.bis. org/speeches/sp100303_es.pdf

MeNDEZ, J.M., PereiRA, J.J., (2009) "La reforma del régimen jurídico de los recursos propios de las entidades de crédito, su impacto en las Cajas de ahorros", Papeles de Economía Española, n 122 "Crisis y regulación financiera".

PoveDA, R., (2010) Basilea II, Madrid, FUNCAS.

Rodríguez, E., (2010) "Las nuevas medidas de Basilea III en materia de capital", Estabilidad financiera $\mathrm{N}^{\circ} 19$, Banco de España, Madrid.

WelLINK, N., (2010), "Un nuevo panorama regulador", $16^{a}$ Conferencia Internacional de Supervisores Bancarios. http://www.riesgooperacional.com/docs/ Articulo_de_la_semana/Un_Nuevo_Panorama_Regulador.pdf

- (2011), "The New Framework for Banking Supervision" http:// www.bis.org/ speeches/sp1 10127.pdf 